\title{
Multi-array analysis of volcano-seismic signals at Fogo and Brava, Cape Verde
} Carola Leva ${ }^{1}$, Georg Rümpker ${ }^{1}$ and Ingo Wölbern ${ }^{1}$

${ }^{1}$ Institute of Geosciences, Goethe-University Frankfurt, Altenhöferallee 1, 60438 Frankfurt am Main, Germany

Correspondence to: Carola Leva (leva@geophysik.uni-frankfurt.de)

\begin{abstract}
Seismic arrays provide tools for the localization of events without clear phases or events outside of the network, where the station coverage prohibits classical localization techniques. Beamforming allows the determination of the direction (backazimuth) and the horizontal (apparent) velocity of an incoming wavefront. Here we combine multiple arrays to retrieve event epicenters from the area of intersecting beams without the need to specify a velocity model. The analysis is performed in the time-domain, which allows to select a relatively narrow time window around the phase of interest while preserving frequency bandwidth. This technique is applied to earthquakes and hybrid events in the region of Fogo and Brava, two islands of the southern chain of the Cape Verde archipelago. The results show that the earthquakes mainly originate near Brava whereas the hybrid events are located on Fogo. By multiple-event beam-stacking we are able to further constrain the locations of the hybrid events in the north-western part of the collapse scar of Fogo. In previous studies, these events were attributed to

15 shallow hydrothermal processes. However, we obtain relatively high apparent velocities at the arrays, pointing to either deeper sources or to complex ray paths. For a better understanding of possible errors of the multi-array analysis, we also compare slowness values obtained from the array analysis with those derived from earthquake locations from classical (local network) localizations. In general, the results agree well, however, the arrays also show some aberrations that can be quantified for certain event locations.
\end{abstract}

\section{Introduction}

Many typical volcano-seismic signals, such as long-period events or tremors, lack clear and impulsive phases. To retrieve information about the characteristics of these events, including their hypocenters, multiple small-aperture seismic antennas have been utilized in past studies at different volcanoes. For example, Almendros et al. (2001a,b) were able to resolve a detailed 3D image of the source region of long-period events at Kilauea, Hawaii, using three arrays. The same arrays were used to discriminate between different wave field components of Kilauea volcano, such as background tremor or surface waves (Almendros et al., 2002). The source of explosion quakes at Stromboli volcano, Italy, could be located using two seismic antennas (La Rocca et al., 2004). Also Etna, Italy, has been the subject to multi-array studies. For example, Saccorotti et al. (2004) deployed two arrays in 1999 to locate sources of tremor during a decreasing eruptive activity. The tremor of the 2004 2005 eruption has been the subject of the double seismic antenna study of Di Lieto et al. (2007). Almendros et al. (2007) provided a model of the possible causes of seismicity during the seismic crisis of Teide volcano, Tenerife, in 2004 using three 
https://doi.org/10.5194/se-2021-52

Preprint. Discussion started: 4 May 2021

(c) Author(s) 2021. CC BY 4.0 License.

arrays. The sources and mechanism of vulcanian explosions of Ubinas volcano, Peru, were analysed with two seismic antennas by Inza et al. (2014). In 2014 the VolcArray study has been performed at Piton de la Fournaise, La Réunion, with three seismic arrays, each consisting of 49 stations (Brenguier et al., 2016). By applying array techniques and ambient noise cross correlations, multipath body waves could be separated and direct and reflected surface waves were extracted (Nakata et al.,

35 2016). The data from the same arrays have also been used by Mao et al. (2019) who monitor relative changes of the velocity in the shallow crust and by Takano et al. (2020) who are able to resolve velocity changes below the detection limit of geodetic measurements from ballistic waves. These examples represent only a small selection of multi-array studies at volcanoes, however, they are indicative of a wide range of possible applications.

In this study we use multiple seismic arrays to investigate the seismic activity of Fogo and Brava. The two islands are located

40 in the southwest of Cape Verde (see inset Fig. 1), about $700 \mathrm{~km}$ west of Senegal in the Atlantic Ocean. Their volcanic origin is attributed to a mantle plume beneath the islands (Courtney and White, 1986). Fogo volcano shows frequent eruptions with intervals of about 20 years, where the last took place from November 2014 to February 2015 (González et al., 2015). This is in contrast to the other volcanoes of the Cape Verde islands, which did not experience eruptions since the settlement in $15^{\text {th }}$ century. Nevertheless, there is evidence for volcanic activity beneath and around the western islands of both (northern and southern) chains of the Cape Verde. The activity occurs either beneath the islands or offshore in fields of submarine volcanic cones, including the Cadamosto Seamount southwest of Brava (Faria and Fonseca, 2014; Vales et al., 2014; Leva et al., 2020). It also involves the high seismic activity beneath and around Brava. This seismicity is characterized by a shift in location over time and frequent variations in the intensity of the seismic activity (Leva et al., 2020).

Despite the frequent volcanic eruptions, Fogo shows a rather low rate of seismicity compared to its neighbour Brava. In Fogo,

50 we mainly find seismic events with a transition from high to low frequencies and without clear S-phases. This type of event has been described as hybrid event, combining the features of a volcano tectonic event in the signal onset and of a long-period event with respect to the coda (e.g. McNutt, 2000; Wassermann, 2012). The lack of S-phases makes this type of event a good candidate for the analysis with seismic arrays. For the localization of these events we perform a time-domain multi-array analysis. This type of analysis has the advantage of being independent of velocity models. The velocity structure is often very complex in a volcanic regime and there is, so far, no detailed 3D-velocity model available for Fogo volcano or Brava island. The time-domain array analysis allows for the incorporation of a narrow time window while including a broad frequency band (Singh and Rümpker, 2020; Leva et al., 2020). Traces are shifted and stacked in the time domain to increase the SNR and to retrieve information about the incoming wavefront. This information includes the backazimuth of the ray path, pointing towards the direction of the incoming wavefront, and the magnitude of the slowness, which is defined as the inverse of the

60 apparent velocity of the wavefront travelling across the array (Rost and Thomas, 2002). Including multiple arrays allows the localization of the event in the area of the intersected beams. In our study, we operated three arrays, two on Fogo, one on Brava, and seven short-period single stations from January 2017 to January 2018. We focus on volcano-tectonic earthquakes originating in the study area around Brava and Fogo, and on hybrid events occurring on Fogo. However, seismic arrays can exhibit systematic aberrations of backazimuth and slowness values. To investigate the aberrations of the three arrays of our 
https://doi.org/10.5194/se-2021-52

Preprint. Discussion started: 4 May 2021

(c) Author(s) 2021. CC BY 4.0 License.

(c) (i)

65 study, we compare multi-array localizations with locations derived from standard (network-based) localization techniques. These standard techniques are based on the picking of P-and S-phases. For this comparison, earthquakes occurring within the network are chosen, i.e. earthquakes beneath or close to Brava or Fogo.

\section{Network}

From 18 January 2017 to 12 January 2018 we operated a total of 37 seismic stations on Fogo and Brava (see Fig. 1). Our

network comprised three arrays each consisting of 10 stations. Two arrays were deployed on Fogo close to the villages of Achada Furna (AF) and Curral Grande (CG), the third one on Brava (BR). Another seven stations were operated as single short-period stations to complement the network - two on Brava, five on Fogo.

The arrays were designed for events with frequencies between 5 and $10 \mathrm{~Hz}$. Each array is circular and consists of a central station with two concentric rings with diameters of $700 \mathrm{~m}$ and $350 \mathrm{~m}$, respectively. Four of the ten stations at each array are equipped with broad-band stations, the other six stations with $4.5 \mathrm{~Hz}$ short-period sensors (see lower right inset map in Fig. 1). As we expect events with mean frequencies between 5 and $10 \mathrm{~Hz}$, the array is optimized for mean frequencies of $7.5 \mathrm{~Hz}$. The array transfer function for $7.5 \mathrm{~Hz}$ is shown in the supplementary material (Fig. S1). It shows a single sharp maximum of energy and only minor secondary peaks. The circular shape of the array leads to a circular, symmetric peak in energy, which allows the detection of incoming wave fronts from any direction.

\section{Method and data analysis}

Criteria for applicability of the classical localization of earthquakes are clear phases of the signal and a network distributed around the origin of the signal. If these criteria are not met, array techniques can help to locate the seismic event. By beamforming backazimuth and absolute slowness are determined from the horizontal components of slowness. For this purpose, the coherent part of the signal is shifted in time and summed up (Rost and Thomas, 2002). This method is based on

85 the assumption, that the wavefront approaching the array approximates a plane wave, which is a valid assumption if the distance between array and source is considerably larger than about ten times the wavelength of the signal (Schweitzer et al., 2012). Performing an array analysis for local events using only one array necessitates an epicentral distance estimation. In a previous study, we determined the epicentral distance based on the S-P-travel time difference. We also assumed a simplified two-layer velocity model and a fixed event depth (for details see Leva et al., 2020). However, this approach may cause significant uncertainties in the localization due the choice of the velocity model. In the present study, to overcome this limitation, we perform a multi-array analysis. This allows the intersection of the beams of each array, which provides the expected location of an event within the area of overlap. A main advantage of this method is its independence of a velocity model.

\subsection{Beamforming}

The array analysis is performed in the time-domain. The time-domain analysis is equivalent to the incorporation of a wide frequency band, while the stacking window is kept narrow around the relevant phase, e.g. the first arrival of the incoming 
https://doi.org/10.5194/se-2021-52

Preprint. Discussion started: 4 May 2021

(c) Author(s) 2021. CC BY 4.0 License.

signal (Singh and Rümpker, 2020; Leva et al., 2020). Traces are first band-pass filtered within the dominant frequencies of the signal (Fig. 2). The cut-off frequencies are chosen in view of the waveform spectrogram. Following, an analysis window is chosen around the first onset of the signal. For the local events we analyse in this study this is typically in the range of one to two seconds. This is shown in Fig. 3a for an example earthquake at array AF. Later, traces will be shifted within this window in reference to the trace of the central array station. A stacking window (in red in Fig. 3a) of one or two periods length around the signal onset marks the phase, for which the beamforming is performed. All windows are chosen in reference to the central array station. The trace of the central station is kept fixed during the time-shift of the remaining traces. This time-shift is performed by a grid search with slowness values from -0.3 to $0.3 \mathrm{~s} / \mathrm{km}$ and a grid size of $124 \times 124$. For each grid node traces are shifted accordingly and summed up. The resulting energy stack is shown in Fig. 3b. The slowness components $s_{x}$ and $s_{y}$ of the maximum energy are further used to determine slowness and backazimuth of the event. Slowness, apparent velocity, and backazimuth are estimated with $s=\sqrt{s_{x}^{2}+s_{y}^{2}}, v_{a p p}=1 / s$, and $B A Z=90^{\circ}-\arctan \left(s_{x} / s_{y}\right)$, respectively. The traces, which are shifted according to the determined slowness of the event, and the corresponding sum trace are displayed in Fig. 3c. The analogue procedure for array BR is shown in Fig. 4a-c and for array CG in Fig. 5a-c.

The slowness is related to the angle of incidence by $\sin (i)=s \cdot v_{c}$, with the mean crustal velocity $v_{c}$. Thus, the lower the

110 slowness, the steeper the wavefront arrives at the array. For near-vertical angles of incidence, the slowness $s$ becomes close to zero and the apparent velocity approaches infinity.

\subsection{Multi-array analysis}

After determining the energy grid of each array, the beams are intersected in the next step to obtain the earthquake location from the multi-array analysis. The standard deviation of the maximum energy is estimated in dependence of the chosen stacking

115 window by randomly varying the start and end times of the stacking window 100 times by values between $-0.2 \mathrm{~s}$ and $0.2 \mathrm{~s}$. The values of $\pm 0.2 \mathrm{~s}$ for the variation of the start and end times of the stacking window were chosen after performing tests with values between $\pm 0.1 \mathrm{~s}, \pm 0.2 \mathrm{~s}$ and $\pm 0.5 \mathrm{~s}$. For the variation of $\pm 0.1 \mathrm{~s}$ the standard deviation becomes very small. There is nearly no deviation from the original result, which means the resulting error is very likely underestimated and not reliable. Regarding the fact that some stacking windows are as small as $0.6 \mathrm{~s}$ the variation of $\pm 0.5 \mathrm{~s}$ proves to be too large and often leads to stacking

120 windows far away from the signal phase of interest. Backazimuth and slowness values, thus, exhibit deviations that are far too large. Examples of the stack of the 100 energy estimations are shown in Fig. 3d for array AF, Fig. 4d for array BR and Fig. $5 \mathrm{~d}$ for array CG. In some cases (like in Fig. 4d for array BR and in Fig. 5d for array CG) the main beam broadens, pointing to a higher sensitivity of the event at the specific array to the choice of the stacking window. If the stack of the 100 energy estimations is comparable to the original energy stack (like in Fig. 3d for array AF), the choice of the stacking window has nearly no impact on the determined beam.

The standard deviation of the slowness value is used as the error of the slowness at each array. In the next step the beam is determined. For this, we chose the minimum and maximum backazimuth values corresponding to the standard deviation of the 
https://doi.org/10.5194/se-2021-52

Preprint. Discussion started: 4 May 2021

(c) Author(s) 2021. CC BY 4.0 License.

(c) (i)

backazimuth. The beam is plotted between these values, which means it is not assumed as a straight line, but rather broadened, taking into account possible uncertainties. The two values within which the beam is plotted are referred to as the outer range

of the beam from here on. Due to possible errors and aberrations of the main beam, we do not expect that all three main beams intersect in the same point where "main beam" refers to the beam with the maximum energy. We also take into account the shape of the energy plot. The backazimuth range defined above is used to plot the related beam. However, a depiction of the beam energy with higher resolution would be desirable. To achieve this, we further intersect the broad beam in steps of $1 \%$ of the standard deviation. The steps of $1 \%$ have been chosen, because in this case the beam is finely split up, while keeping the computing time in reasonable limits. Practically spoken, the broad beam is overlain by a second beam with a width of $99 \%$ of the standard deviation, then by a third beam of $98 \%$ of the standard deviation and so on. Now 100 beams overlay each other, getting smaller towards the main beam. These 100 beams need different values to allow the determination of the location with the highest probability when intersecting the beams of different arrays. The broadest beam, i.e. the beam with the width of the standard deviation, is assigned the smallest value and the narrowest beam, with a width of $1 \%$ of the standard deviation, the

140 highest value. Thus, we assign values from 1 to 100 to each of the steps.

Now these beams are transferred to a map spanning the geological coordinates of the research area, with the array location as origin of the corresponding beam. The maximum value, which can theoretically be reached when intersecting the three beams, is used to normalize their values. After intersecting the beams, the area with the highest probability of the event location is determined. The last step is to choose a narrower map section including the coordinates of the arrays and of the highest probability determined in the step before. The section now has a finer grid, the highest probability is again estimated and represents the location of the event (Fig. 6).

We choose a confidence interval of $90 \%$ of the maximum value of the intersected area as error for the multi-array analysis.

\section{Results}

The majority of the recorded events are local volcano-tectonic earthquakes mainly occurring in the area of Brava. However, we also observe hybrid events which are recorded by the stations on Fogo. Figure 7 shows traces and spectrograms of these two types of events.

\subsection{Earthquakes}

The volcano-tectonic earthquakes on average occur 8 times a day (see Fig. 8a). The rate of seismicity frequently increases, leading to phases with elevated seismic activity. 2709 earthquakes were recorded from 18 January 2017 to 12 January 2018, 155112 of which could be located using multi-array techniques. The earthquakes mainly occurred around Brava (Fig. 9). The reason for the discrepancy of the amount of detected and with the multi-array analysis located earthquakes are manifold. Many smaller earthquakes are recorded with our stations only on Brava, thus precluding the multi-array analysis, as for this at least two arrays must detect the event. As described further in Sect. 4.3, the multi array analysis can only be performed for events with stable results for the backazimuth determination. If the energy grid shows e.g. strong side lobes or the choice of slightly 
https://doi.org/10.5194/se-2021-52

Preprint. Discussion started: 4 May 2021

(c) Author(s) 2021. CC BY 4.0 License.

(c) (i)

different stacking windows for the same event leads to strongly different results, the result of this array for this particular event is discarded. Additionally, at least two arrays must show reliable and stable results, which further reduces the number of located events. The recordings of the stations on Fogo show a rather high frequency content with the main frequencies between 10 to $30 \mathrm{~Hz}$ (Fig. 7a). On Brava the dominant frequencies of the same event are lower and range between 2 and $20 \mathrm{~Hz}$. The corresponding spectrum is shown in the supplementary material (Fig. S2b).

165 The mean apparent velocities at the arrays on Fogo are in the range of $7.1 \mathrm{~km} / \mathrm{s}$ for events originating close to Brava. In a medium with lateral homogeneous velocities, the apparent velocity is equivalent to the velocity of the ray turning point. Apparent velocities $<8 \mathrm{~km} / \mathrm{s}$ thus point to a ray turning point within the crust (velocity model taken from Vales et al., 2014), indicating crustal depths of the earthquakes. Note that the array on Brava shows higher apparent velocities for the same earthquakes with a mean of $10.8 \mathrm{~km} / \mathrm{s}$. However, array BR is located closely to the sources, which results in a steeper angle of incidence (and smaller slowness) compared to the arrays located on Fogo.

\subsection{Hybrid events}

The hybrid events observed on Fogo (see Fig. 8b) are characterized by high frequencies (15-40 Hz) at the beginning of the signal, followed by low frequencies $(1-10 \mathrm{~Hz})$ and a lack of clear S-phases. The signals mainly last about 20 to 30 seconds, some last up to 1 minute, and usually reach station CV10 first, where they also show the largest amplitudes. Figure $7 \mathrm{~b}$ shows an example event recorded at a broad-band station of the array AF. Vertical traces of such an event are displayed in the supplementary material (Fig. S3). As the events were only recorded by the stations on Fogo, they were located using the arrays AF and CG. We observe 125 hybrid events, 12 of which could be located. Figure 10a shows the resulting locations, in or close to the collapse scar of Fogo, Chã das Caldeiras. The events exhibit rather high apparent velocities, in average $7.8 \mathrm{~km} / \mathrm{s}$ at array $\mathrm{AF}$ and $8.4 \mathrm{~km} / \mathrm{s}$ at array CG. The mean errors of these velocities are $2.9 \mathrm{~km} / \mathrm{s}$ and $2.8 \mathrm{~km} / \mathrm{s}$ at array AF and CG, respectively.

180 To determine the source location of the hybrid events, we superimpose the beams of all localizations of the hybrid events (Fig. $10 \mathrm{~b}$, the area with probabilities above $80 \%$ of the maximum stacked probability is marked with a white line). We find this area in the north-western part of Chã das Caldeiras.

\subsection{Error considerations}

Different factors have an influence on the uncertainty of the result of the multi-array analysis. They can be divided into two 185 categories: uncertainties related to the parameters of the array analysis and due effects of the ray paths. Parameters in connection with the analysis are the frequency range of the data and the length of the stacking window. Effects along the ray path from the source to the array, such as heterogeneities, can result in a systematic aberration of the array.

To test for the influence of the chosen stacking window and the frequencies, multiple repetitions of the analysis at one array are computed with a random variation of these parameters. Results concerning the variation of the stacking window are

190 accounted for as described in Sect. 3.2. The same analysis has been performed for varying cut-off frequencies. For earthquakes the lower frequency is randomly varied between 2 and $8 \mathrm{~Hz}$, the upper frequency between 15 and $30 \mathrm{~Hz}$. For hybrid events the 
https://doi.org/10.5194/se-2021-52

Preprint. Discussion started: 4 May 2021

(c) Author(s) 2021. CC BY 4.0 License.

variation was between 1 and $4 \mathrm{~Hz}$ and 10 to $20 \mathrm{~Hz}$ for the lower and upper frequencies, respectively. The analysis is done 100 times and the resulting standard deviation is again used to display the energy beam in the multi-array analysis. The results for varying cut-off frequencies show a minor influence on the backazimuth, as demonstrated in the supplementary Fig. S4. We conclude that, for a given stacking window, the variation of the frequency band can be neglected in the error determination. The selection of the stacking window has a larger contribution to possible errors and is thus included in the analysis (see Fig. 6).

Velocity heterogeneities beneath the arrays or along the ray paths can possibly lead to a systematic bias in slowness and backazimuth determination (Rost and Thomas, 2002). This aberration of the arrays can be determined by comparing backazimuth and slowness values with those derived from a different localization technique (e.g. Krüger and Weber, 1992; Schweitzer et al., 2012). With respect to local events, we decided to locate earthquakes with a classical analysis (using the HYPOCENTER code of Lienert et al., 1986) by including all single stations of our network and one station of each array. For this standard localization technique, we apply the velocity model from Vales et al. (2014). To ensure the reliability of the classical localization, only earthquakes within or very close to the network were used. This comprises only earthquakes beneath Brava, Fogo and those located between the islands. Additionally, we only used results for which the rms values and errors of the classical analysis are small ( $\mathrm{rms}<0.25$, errors $<5 \mathrm{~km}$ in longitude, latitude and depth). In total, a number of 13 events fulfilled all criteria and could be used for the comparison. The (theoretical) backazimuth and slowness values of these events are determined at the different arrays and compared to the respective values of the array analysis. The components of the resulting vectors, pointing from the backazimuth and slowness value of the array analysis (red points) towards the respective values from the classical analysis (green points), are displayed in Fig. 11. In the range of $240^{\circ}-270^{\circ}$, array AF systematically yields backazimuths pointing too far to the south by about $7^{\circ}$ and array CG shows backazimuth values too far to the north with a mean aberration of about $9^{\circ}$. The array on Brava shows a variety of deviations due to the many directions of incoming waves. It appears, that backazimuth values in the range of $270^{\circ}-360^{\circ}$ point too far to the north. However, for the comparison with the classical localization, there are only four events within this range, prohibiting a reliable statement on systematic aberrations.

215 For a successful localization with multiple arrays certain requirements need to be fulfilled. For example, the stacking windows at each array should contain the same phase of the signal (Almendros et al., 2002). To ensure this, we perform the multi-array analysis on the first onset of the signal. Additionally, the occurrence of strong side lobes in the energy stack must be avoided as the occurrence of secondary peaks results in two or even more beams at one array. This may lead to event mislocations. Furthermore, the occurrence of strong side lobes generally indicates higher uncertainties in results. Regarding the intersection of the beams additional considerations must be taken into account. If beams trend almost parallel, the epicentre will be located far away with a large uncertainty in distance (see Fig. 12a,b). Furthermore, if two beams point from one array to another, the whole area between the arrays will be a potential source region, leading to large errors in the localization (see Fig. 12c,d). In these two cases the third array is of particular importance, as it will strongly narrow down the area of the likely source. If the third array does not provide any additional information in such cases the localization of the corresponding event must be discarded due to the high level of uncertainty. Also, considering that the arrays show small but systematic aberrations, it is not 
https://doi.org/10.5194/se-2021-52

Preprint. Discussion started: 4 May 2021

(c) Author(s) 2021. CC BY 4.0 License.

unlikely to find a result, where the three beams do not overlap in the same area. To be able to assess the reliability of the location obtained during the analysis, information about the epicentral distance are added to the map of the intersecting beams. This can be used especially for the analysis of earthquakes: Here, S- to P-traveltime differences are determined for each array and plotted as circles around the array (see Fig. 13). For this estimation we apply a two-layer velocity model with a mean crustal and a mean mantle velocity and a fixed event depth of $5 \mathrm{~km}$ (see Leva et al., 2020). This fixed event depth has been defined after estimating a mean event depth from previous studies of the region around Brava (Faria and Fonseca, 2014). However, this information about the epicentral distance is not included in the localization, as we want to retrieve the source location without applying a velocity model. It only serves as a reference for the analyst to evaluate whether or not the estimated source location is reasonable. Due to the lack of S-phases this estimate is not used during the analysis of hybrid events. However, here the array locations with respect to the event locations is very favourable, as the beams intersect almost perpendicular. This prevents the occurrence of parallel trending beams and beams pointing towards each other.

\section{Discussion}

Most earthquakes occur around and beneath Brava and the seismic activity shows several periods with increased seismicity (Fig. 8a). This is a common observation for the seismicity around Brava (Faria and Fonseca, 2014; Vales et al., 2014; Leva et al., 2020). The earthquakes originate in the crust as derived from the apparent velocity. It is worth noting, that the frequency content of the earthquake recordings on Brava show in general lower dominant frequencies (supplementary material Fig. S2b) than the recordings of the same events on Fogo (Fig. 7a). This is surprising, as in a volcanic regime high frequencies are typically more attenuated. On the other hand, observation of high-frequency tremor around Fogo has been described by Heleno et al. (2006). These authors report on the conservation of high frequencies in a tremor signal even at larger distances (about 15

$245 \mathrm{~km}$ ) from the source. In September we observe some earthquakes beneath Fogo (see Fig. 9) which occur within the shallow crust according to the apparent velocities measured at the arrays and the S- to P-travel time differences. These events are located close to the area, where deep subcrustal earthquakes have been observed in August 2016 (see Fig. S5; Leva et al., 2019). Nevertheless, due to their large difference in depth and the long amount of time between these two occurrences, we cannot establish a link between them (as due to the transport of magma from depth into the crust).

250 Apart from the earthquakes in September, Fogo mainly shows volcanic seismic signals, which are best described as hybrid events (in total 125 in 2017). Their origin is located in the north-western part of the collapse scar of Fogo and on top of the Bodeira wall, which surrounds large parts of the collapse scar Chã das Caldeiras. It has been discussed in previous studies (e.g. McNutt, 2000; Wassermann, 2012) that these events are caused by a combination of source mechanisms relevant for volcanotectonic earthquakes and long-period events. One such hypothesis is a volcano-tectonic earthquake, which triggers the oscillation of a fluid-filled cavity (McNutt, 2000). At Fogo, hybrid events have been detected before (Faria and Fonseca, 2014). They were attributed to hydrothermal processes at shallow depths (several hundred meters), due to the interaction of rainwater and hot rock. This hypothesis is based on the seasonal variation of the number of hybrid events and a water table found at 370 $m$ depth in the Chã das Caldeiras. We observe a variation in the number of events over the year of observation and compared 
https://doi.org/10.5194/se-2021-52

Preprint. Discussion started: 4 May 2021

(c) Author(s) 2021. CC BY 4.0 License.

it with the amount of precipitation per month in 2017. The corresponding figure is shown in the supplementary material (Fig.

S6). We find an increase of hybrid events from February to March and from June to September. The precipitation shows a small peak in March, which might correspond to the peak of hybrid events. However, the strongest peak of precipitation occurs in August. This does not directly correlate with the maximum peak in the number of hybrid events, which occurs in November. From this, we conclude that a causal relationship between precipitation rates and the occurrence of hybrid events cannot be established.

High apparent velocities of the hybrid events indicate steep angles of incidence, possibly pointing to a deep seated source. With the multi-array analysis, it is not possible to estimate the depth of the events. However, assuming a simple velocity model (adapted from Vales et al., 2014) with increasing velocity steps of $0.1 \mathrm{~km}$ we derive the ray path from the angle of incidence at the array until the epicentral distance is reached. This simple model yields event depths of 5 to $14 \mathrm{~km}$. Additionally we considered other velocity models, which might be better suited regarding the expected complex velocity structure. Adapting a velocity model for Etna (Almendros et al., 2000) yields event depths between 10 and $20 \mathrm{~km}$. The use of the velocity model for the caldera of Tenerife (Lodge et al., 2012) yields results between 3.5 and $15 \mathrm{~km}$. This shows the very large impact of the velocity model on the estimation of the angle of incidence at the array and the computed ray path. The event depths estimated from the slowness values observed at the arrays and the different velocity models would be significantly deeper than the depths reported in previous studies. There can be several reasons for such an observation. It is possible, that the source of the events has shifted to greater depths after the eruption of Fogo in 2014. This might also explain, why there is no direct correlation between the precipitation data of 2017 and the number of hybrid events. Another possibility is that the wave field is affected by path effects caused by the complex structure of the volcanic edifice (Kedar et al., 1996). These authors suggest, that a single pulse can trigger seismic waves, which then interact with heterogeneities in the elastic, loosely consolidated surrounding layers of the volcanic edifice, leading to complex harmonic seismic signals at the receiver. Such an effect is hard to discriminate from an oscillating resonator. Finally, Harrington and Brodsky (2007) provide the explanation that hybrid events are not necessarily caused by fluid motion, but by brittle failure. Low rupture velocities and strong path effects result in the long low-frequency coda. On Fogo, this brittle failure at shallow depths could be caused by gravity loadings in the collapse scar after the latest eruption. From these considerations, we conclude that scattering effects along the ray path may explain the pattern of the observed hybrid events on Fogo, i.e. the clear signal onset, the lack of S-phases and the smooth transition from high to low frequencies without the appearance of definite dominant frequencies.

A complex ray path might also affect the slowness measured at the arrays. Almendros et al. (2001a) evaluate the influence of a complex 3D velocity structure of Kilauea, Hawaii, on the apparent velocity recorded at a seismic array. The results point to a partly strong reduction of the slowness values in comparison to a homogenous velocity model. It is likely that the complex velocity structure of Fogo has an impact on the ray path and thus leads to slowness variations. This bias could possibly result in smaller slowness values and, thus, explain the high apparent velocities we measure. However, the assumed uncertainties of the apparent velocities are rather large and should cover this bias. In addition to these considerations, we observe strong differences in the amplitudes at the stations. The amplitudes of hybrid events at station CV10 in the collapse scar are nearly 
https://doi.org/10.5194/se-2021-52

Preprint. Discussion started: 4 May 2021

(c) Author(s) 2021. CC BY 4.0 License.

(c) (i)

twice as large as the amplitudes of the other stations on Fogo, not located this close to the source. The second station CV14 in the collapse scar was only operational during the last three months of the study. However, for the few events detected in this period, the amplitudes at CV14 are in the range of those at CV10, but the signal arrives slightly later than at station CV10. If the events would actually occur in depths of 5 to $14 \mathrm{~km}$, we would not expect such a large difference in the amplitude ratios. We thus conclude, that despite the high apparent velocities, the hybrid events should actually originate from shallower depths, as already suggested by previous authors (Faria and Fonseca, 2014). Nevertheless, a hydrothermal origin may not be necessary to explain their occurrence and their real cause remains unclear. The use of a high resolution 3D velocity model or a dedicated dense network of stations placed near the observed epicenters could contribute to a better understanding of these events, as it would allow for a more precise depth estimate.

Being independent of any velocity model and able to locate events without clear onset of phases or offshore, outside of the network, are strong advantages of the utilization of multiple seismic arrays. However, there are certain limitations of the multiarray analysis. The arrays on Fogo and Brava show a systematic deviation, which has been estimated by a comparison with classically located events. The number of reference events (in total 13) is too small for a correction of backazimuth and slowness values during the analysis. However, some relevant conclusions can still be drawn for the utilization of the multiarray technique. At the arrays AF and CG on Fogo wavefronts arrive from a range of backazimuths of $240^{\circ}$ to $270^{\circ}$ (see supplementary Fig. S7.1). Within this range of backazimuth values array AF shows a mean aberration to the south of $7^{\circ}$ and CG a mean aberration to the north of $9^{\circ}$. For the array BR on Brava observed backazimuth values cover a wide range (see supplementary Fig. S7.1) and slowness values can be small for events close to the array. Figure 11 shows larger aberrations of backazimuth and slowness for events with slowness values below $0.1 \mathrm{~s} / \mathrm{km}$. The question arises, if the results of array BR should generally be discarded when they show slowness values below $0.1 \mathrm{~s} / \mathrm{km}$. However, the beams related to the arrays on Fogo can easily trend parallel, leading to an over-estimated epicentre distance. Therefore, the beam of the array on Brava is essential, as it usually locates the event closer to the expected location. This is shown in Fig. 12a,b. Generally, the errors in the events location, which result from the uncertainties of the backazimuth determination at array BR are by far smaller than the errors when using only the arrays on Fogo. The distance estimated from the S- to P-traveltime difference serves as verification of the epicentral distance determined by the multi-array analysis. This is especially helpful when only two arrays are available for a localization. Thus, a multi-array analysis using only two arrays is still possible, but might lead to a certain amount of earthquakes that cannot be located due to the aberration of backazimuth values. For the hybrid events on Fogo, the determination of the aberration vectors is not possible due to the lack of reference localizations. The distribution of backazimuth values of the hybrid events is displayed in the supplementary material (Fig. S7.2). The backazimuth values clearly indicate a location close to or in the collapse scar of Fogo. Nevertheless, a possible aberration should not lead to large errors in the localization, because of the location of the arrays with respect to the source region. 
https://doi.org/10.5194/se-2021-52

Preprint. Discussion started: 4 May 2021

(c) Author(s) 2021. CC BY 4.0 License.

(c) (i)

\section{Conclusion}

325 From January 2017 to January 2018 we operated three arrays on Fogo and Brava to apply a time-domain multi-array analysis for seismic events occurring in this region. This application allows the event localization without assuming a velocity model. This is a significant advantage in a volcanic regime, where the velocity structure is difficult to constrain. Additionally, we are able to locate offshore earthquakes outside of the network and hybrid events without clear S-phases. Although the application of the time-domain multi-array analysis has many benefits, it is necessary to evaluate possible errors of the localization, which may result from systematic aberrations of the arrays. These deviations can be caused by heterogeneities along the ray path. To determine the aberrations of backazimuth and slowness values, we compare them to those derived from a classical earthquake analysis. It turns out, that the number of reference events is too small for a reliable correction. We therefore allow for relatively large location uncertainties to cover the possible aberrations.

A large number of volcano-tectonic earthquakes are located beneath and around Brava. As reported previously (Faria and

335 Fonseca, 2014; Vales et al., 2014; Leva et al., 2020), we observe several periods of elevated seismic activity and a frequent shift of locations around the island. Additionally, a few earthquakes occur beneath Fogo in the shallow part of the crust. Some of them occur in the shallow crust in approximately the same epicentral area as deep subcrustal earthquakes of 2016 (Leva et al., 2019). However, a conclusion concerning a possible link between these two occurrences could not be made due to the rareness of such earthquakes. However, the majority of seismic events beneath Fogo are hybrid events. As shown by a joint

340 analysis of the events, their epicenters are close to the north western part of the Chã das Caldeiras and beneath the Bodeira wall. These events show significantly larger apparent velocities than the volcano-tectonic earthquakes recorded with the arrays on Fogo. Most likely, these high values result from the influence of the topography and the complex velocity structure of the volcanic edifice, leading to a possible bias in the slowness determination. Additionally, the station CV10 located in the Chã das Caldeiras shows significantly larger amplitudes than the remaining stations on Fogo. We believe that the origin of the

345 hybrid events is not as deep as the high apparent velocities would suggest. However, the origin remains unclear due to the lack of information about the depth. The application of a precise 3D velocity model or a dedicated local network could shed further light on the depth and thus on the possible source mechanism of these events.

In addition to the volcano-tectonic earthquakes and the hybrid events, we detected isolated instances of volcanic tremor, which we have not yet analysed in detail. This will be subject of forthcoming studies.

\section{Data availability}

The data are available for download at GEOFON (https://geofon.gfz-potsdam.de, GEOFON, 2021). Please refer to Wölbern and Rümpker (2020, https://doi.org/10.14470/4W7562667842). 
https://doi.org/10.5194/se-2021-52

Preprint. Discussion started: 4 May 2021

(c) Author(s) 2021. CC BY 4.0 License.

(c) (i)

\section{Author contributions}

The study and the setup of the seismic arrays were initiated and conceived by IW and GR. IW was also responsible for project

administration. CL analyzed the data and prepared the figures for the here presented work. CL wrote the manuscript as part of her PhD under supervision of GR. The manuscript was revised by GR and IW. All authors took part in the field work.

\section{Competing interests}

The authors declare that they have no conflict of interest.

\section{Acknowledgement}

360 This study has been financed by the Deutsche Forschungsgemeinschaft with a grant to Ingo Wölbern (grant number WO 1723/3-1). The Geophysical Instrument Pool Potsdam provided the instruments. The realisation of this study was possible due to the friendly support of Bruno Faria. Additionally, we would like to thank José Levy for his support and help in customs handling, Paulo Fernandes Teixeira and José Antonio Fernandes Dias Fonseca for supporting us during field work. For their support in the field campaign we also thank Frederik Link, Kristina Drews, Ayoub Kaviani, Joachim Palm, Nils Rümpker and

365 Corrado Surmanowicz.

\section{References}

Almendros, J., Ibáñez, J. M., Alguacil, G., Morales, J., Del Pezzo, E., La Rocca, M., Ortiz, R., Araña, V., and Blanco, M. J.: A double seismic antenna experiment at teide Volcano: existence of local seismicity and lack of evidences of Volcanic tremor, J. Volcanol. Geoth. Res., 103, 439-462, doi:10.1016/S0377-0273(00)00236-5, 2000.

Almendros, J., Chouet, B., and Dawson, P.: Spatial extent of a hydrothermal system at Kilauea Volcano, Hawaii, determined from array analyses of shallow long-period seismicity: 1. Method, J. Geophys. Res., 106(B7), 13565-13580, doi:10.1029/2001JB000310, 2001a.

Almendros, J., Chouet, B., and Dawson, P.: Spatial extent of a hydrothermal system at Kilauea Volcano, Hawaii, determined from array analyses of shallow long-period seismicity: 2. Results, J. Geophys. Res., 106(B7), 13581-13597, doi:10.1029/2001JB000309, 2001b.

Almendros, J., Chouet, B., Dawson, P., and Huber, C.: Mapping the Sources of the Seismic Wave Field at Kilauea Volcano, Hawaii, Using Data Recorded on Multiple Seismic Antennas, Bull. Seismol. Soc. Am., 92, no. 6, 2333-2351, doi:10.1785/0120020037, 2002.

Almendros, J., Ibáñez, J. M., Carmona, E., and Zandomeneghi, D.: Array analyses of volcanic earthquakes and tremor recorded at Las Cañadas caldera (Tenerife Island, Spain) during the 2004 seismic activation of Teide volcano, J. Volcanol. Geoth. Res., 160, 285-299, doi:10.1016/j.jvolgeores.2006.10.002, 2007. 
https://doi.org/10.5194/se-2021-52

Preprint. Discussion started: 4 May 2021

(c) Author(s) 2021. CC BY 4.0 License.

(c) (i)

Brenguier, F., Kowalski, P., Ackerley, N., Nakata, N., Boué, P., Campillo, M., Larose, E., Rambaud, S., Pequegnat, C., Lecocq, T., Roux, P., Ferrazzini, V., Villeneuve, N., Shapiro, N. M., and Chaput, J.: Toward 4D Noise-Based Seismic Probing of Volcanoes: Perspectives from a Large-N Experiment on Piton de la Fournaise Volcano, Seismol. Res. Lett., 87 (1), 15-25. doi:10.1785/0220150173, 2016.

Courtney, R. C., and White, R. S.: Anomalous heat flow and geoid across the Cape Verde Rise: evidence for dynamic support from a thermal plume in the mantle, Geophys. J. Roy. Astr. Soc., 87, 815-867, doi:10.1111/j.1365246X.1986.tb01973.x, 1986.

Di Lieto, B., Saccorotti, G., Zuccarello, L., Rocca, M.L. and Scarpa, R.: Continuous tracking of volcanic tremor at Mount Etna, Italy. Geophys. J. Int., 169, 699-705, doi:10.1111/j.1365-246X.2007.03316.x, 2007.

Faria, B., and Fonseca, J. F. B. D.: Investigating volcanic hazard in Cape Verde Islands through geophysical monitoring: network description and first results, Nat. Hazard. Earth Sys., 14, 485-499, doi:10.5194/nhess-14-485-2014, 2014.

GEOFON: GFZ German Research Center for Geosciences, available at: https://geofon.gfz-potsdam.de, last access: 14 March 2021.

González, P. J., Bagnardi, M., Hooper, A. J., Larsen, Y., Marinkovic, P., Samsonov, S. V., and Wright, T. J.: The 2014-2015 eruption of Fogo volcano: Geodetic modeling of Sentinel-1 TOPS interferometry, Geophys. Res. Lett., 42, 92399246, doi:10.1002/2015GL066003, 2015.

Harrington, R. M., and Brodsky, E. E.: Volcanic hybrid earthquakes that are brittle-failure events, Geophys. Res. Lett., 34, L06308, doi:10.1029/2006GL028714, 2007.

Heleno, S., Faria, B., Bandomo, Z., and Fonseca, J.: Observations of high-frequency harmonic tremor in Fogo, Cape Verde Islands, J. Volcanol. Geoth. Res., 158, 361-379, doi:10.1016/j.jvolgeores.2006.06.018, 2006.

Inza, L. A., Métaxian, J. P., Mars, J. I., Bean, C. J., O'Brien, G. S., Macedo, O., and Zandomeneghi, D.: Analysis of dynamics of vulcanian activity of Ubinas volcano, using multicomponent seismic antennas, J. Volcanol. Geoth. Res., 270, 35-52, doi:10.1016/j.jvolgeores.2013.11.008, 2014.

405 Kedar, S., Sturtevant, B., and Kanamori, H.: The origin of harmonic tremor at Old Faithful geyser, Nature, 379, 708-711, doi:10.1038/379708a0, 1996.

Krüger, F., and Weber, M.: The effect of low-velocity sediments on the mislocation vectors of the GRF array, Geophys. J. Int., 108, 387-393, doi:10.1111/j.1365-246X.1992.tb00866.x, 1992.

La Rocca, M., Saccorotti, G., Del Pezzo, E., and Ibanez, J.: Probabilistic source location of explosion quakes at Stromboli volcano estimated with double array data, J. Volcanol. Geoth. Res., 131, 123-142, doi:10.1016/S03770273(03)00321-4, 2004.

Leva, C., Rümpker, G., Link, F., and Wölbern, I.: Mantle earthquakes beneath Fogo volcano, Cape Verde: Evidence for subcrustal fracturing induced by magmatic injection, J. Volcanol. Geoth. Res., 386, 106672, doi:10.1016/j.jvolgeores.2019.106672, 2019. 
https://doi.org/10.5194/se-2021-52

Preprint. Discussion started: 4 May 2021

(c) Author(s) 2021. CC BY 4.0 License.

(c) (i)

415 Leva, C., Rümpker, G., and Wölbern, I.: Remote monitoring of seismic swarms and the August 2016 seismic crisis of Brava, Cabo Verde, using array methods, Nat. Hazards Earth Syst. Sci., 20, 3627-3638, doi:10.5194/nhess-20-3627-2020, 2020.

Lodge, A., Nippress, S. E. J., Rietbrock, A., García-Yeguas, A., and Ibáñez, J. M.: Evidence for magmatic underplating and partial melt beneath the Canary Islands derived using teleseismic receiver functions, Phys. Earth Planet. In., 212213, 44-54, doi:10.1016/j.pepi.2012.09.004, 2012.

Lienert, B. R., Berg, E., and Frazer, L. N.: HYPOCENTER: An earthquake location method using centered, scaled, and adaptively damped least squares, Bull. Seismol. Soc. Am., 76, 771-783, 1986.

Mao, S., Campillo, M., van der Hilst, R. D., Brenguier, F., Stehly, L., and Hillers, G.: High temporal resolution monitoring of small variations in crustal strain by dense seismic arrays, Geophys. Res. Lett., 46, 128-137, doi:10.1029/2018GL079944, 2019.

McNutt, S.R.: Volcanic Seismicity, Chapter 63 of Encyclopedia of Volcanoes, Sigurdsson, H., B. Houghton, S.R. McNutt, H. Rymer, and J. Stix (eds.), 1st Edition, Academic Press, San Diego, CA, 1015-1033, 2000.

Nakata, N., Boué, P., Brenguier, F., Roux, P., Ferrazzini, V., and Campillo, M.: Body and surface wave reconstruction from seismic noise correlations between arrays at Piton de la Fournaise volcano, Geophys. Res. Lett., 43, 1047-1054, doi:10.1002/2015GL066997, 2016.

Rost, S., and Thomas, C.: Array seismology: Methods and applications, Rev. Geophys., 40 (3), 1008, doi:10.1029/2000RG000100, 2002.

Ryan, W. B. F., Carbotte, S. M., Coplan, J. O., O'Hara, S., Melkonian, A., Arko, R., Weissel, R. A., Ferrini, V., Goodwillie, A., Nitsche, F., Bonczkowski, J., and Zemsky, R.: Global Multi-Resolution Topography synthesis, Geochem. Geophy. Geosy., 10, Q03014, doi:10.1029/2008GC002332, 2009.

Saccorotti, G., Zuccarello, L., Del Pezzo, E., Ibanez, J., and Gresta, S.: Quantitative analysis of the tremor wavefield at Etna Volcano, Italy, J. Volcanol. Geoth. Res., 136, 223-245, doi:10.1016/j.jvolgeores.2004.04.003, 2004.

Schweitzer, J., Fyen, J., Mykkeltveit, S., Gibbons, S. J., Pirli, M., Kühn, D., and Kværna, T.: Seismic Arrays, in: New Manual of Seismological Observatory Practice 2 (NMSOP-2), Bormann, P. (Ed.), Potsdam: Deutsches GeoForschungsZentrum GFZ, 1-80, doi:10.2312/GFZ.NMSOP-2_ch9, 2012.

Singh, M. and Rümpker, G.: Seismic gaps and intraplate seismicity around Rodrigues Ridge (Indian Ocean) from time domain array analysis, Solid Earth, 11, 2557-2568, doi:10.5194/se-11-2557-2020, 2020.

Takano, T., Brenguier, F., Campillo, M., Peltier, A., and Nishimura, T.: Noise-based passive ballistic wave seismic monitoring on an active volcano, Geophys. J. Int., 220, 501-507, doi: 10.1093/gji/ggz466, 2020.

445 Vales, D., Dias, N. A., Rio, I., Matias, L., Silveira, G., Madeira, J., Weber, M., Carrilho, F., and Haberland, C.: Intraplate seismicity across the Cape Verde swell: A contribution from a temporary seismic network, Tectonophysics, 636, 325-377, doi:10.1016/j.tecto.2014.09.014, 2014. 
https://doi.org/10.5194/se-2021-52

Preprint. Discussion started: 4 May 2021

Wassermann, J.: Volcano Seismology, in: New Manual of Seismological Observatory Practice 2 (NMSOP-2), Bormann, P. (Ed.), Potsdam: Deutsches GeoForschungsZentrum GFZ, 1-77, doi:10.2312/GFZ.NMSOP-2_ch13, 2012.

450 Wölbern, I., and Rümpker, G.: FoMapS: Seismic investigation of the Fogo magmatic plumbing system, Cape Verde, using multi-array techniques, GFZ Data Services, doi:10.14470/4W7562667842, 2020.

\section{Figures}

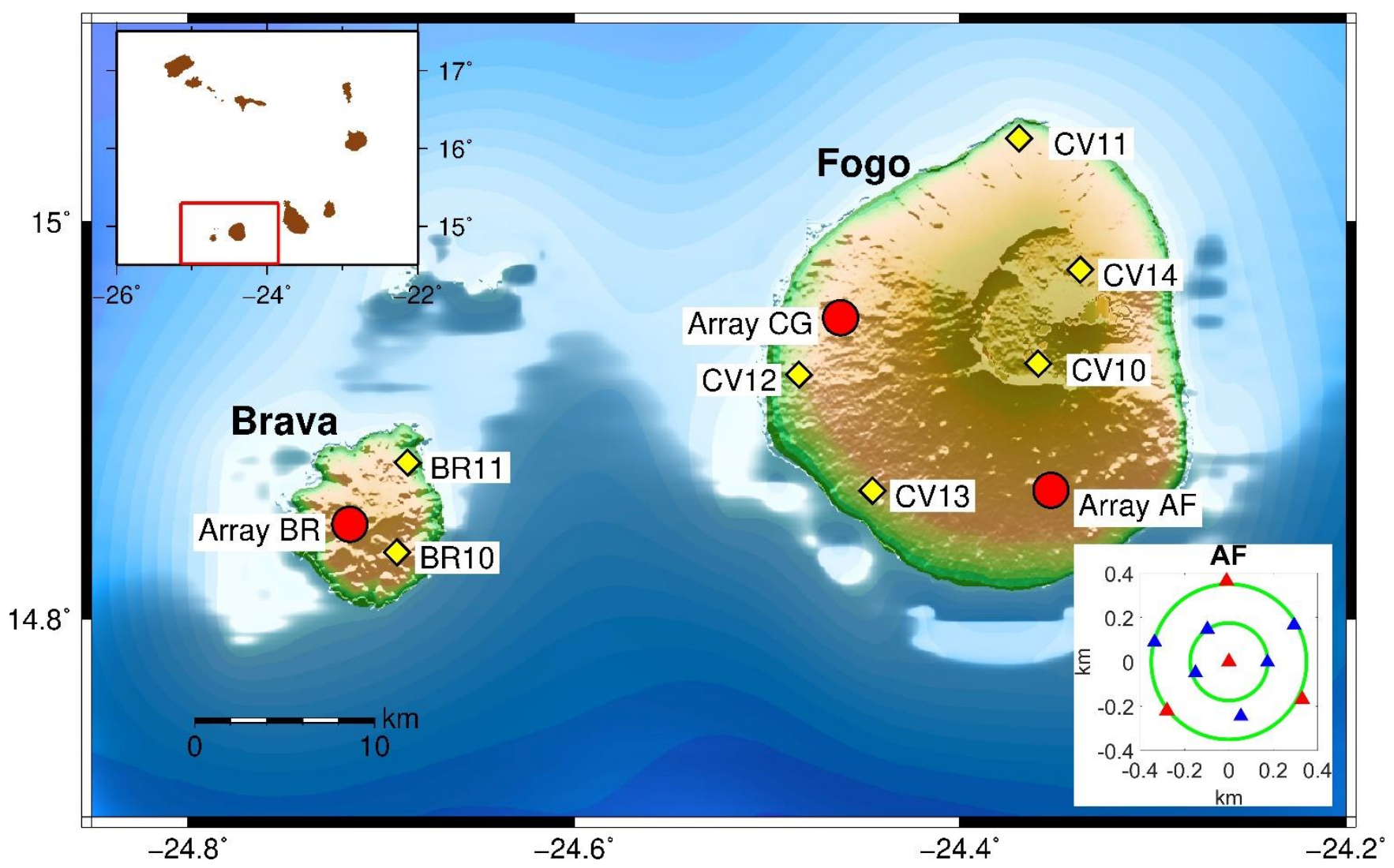

Figure 1: Station configuration on Fogo and Brava from January 2017 to January 2018. Red circles: array locations; yellow diamonds: short-period single stations. Left inset: Cape Verde, current section around Fogo and Brava marked in red. Right inset: setup of the array AF, red: broad-band stations, blue: short-period stations. The arrays BR and CG are designed in the same way. Topographic and bathymetry data are from Ryan et al. (2009). 
https://doi.org/10.5194/se-2021-52

Preprint. Discussion started: 4 May 2021

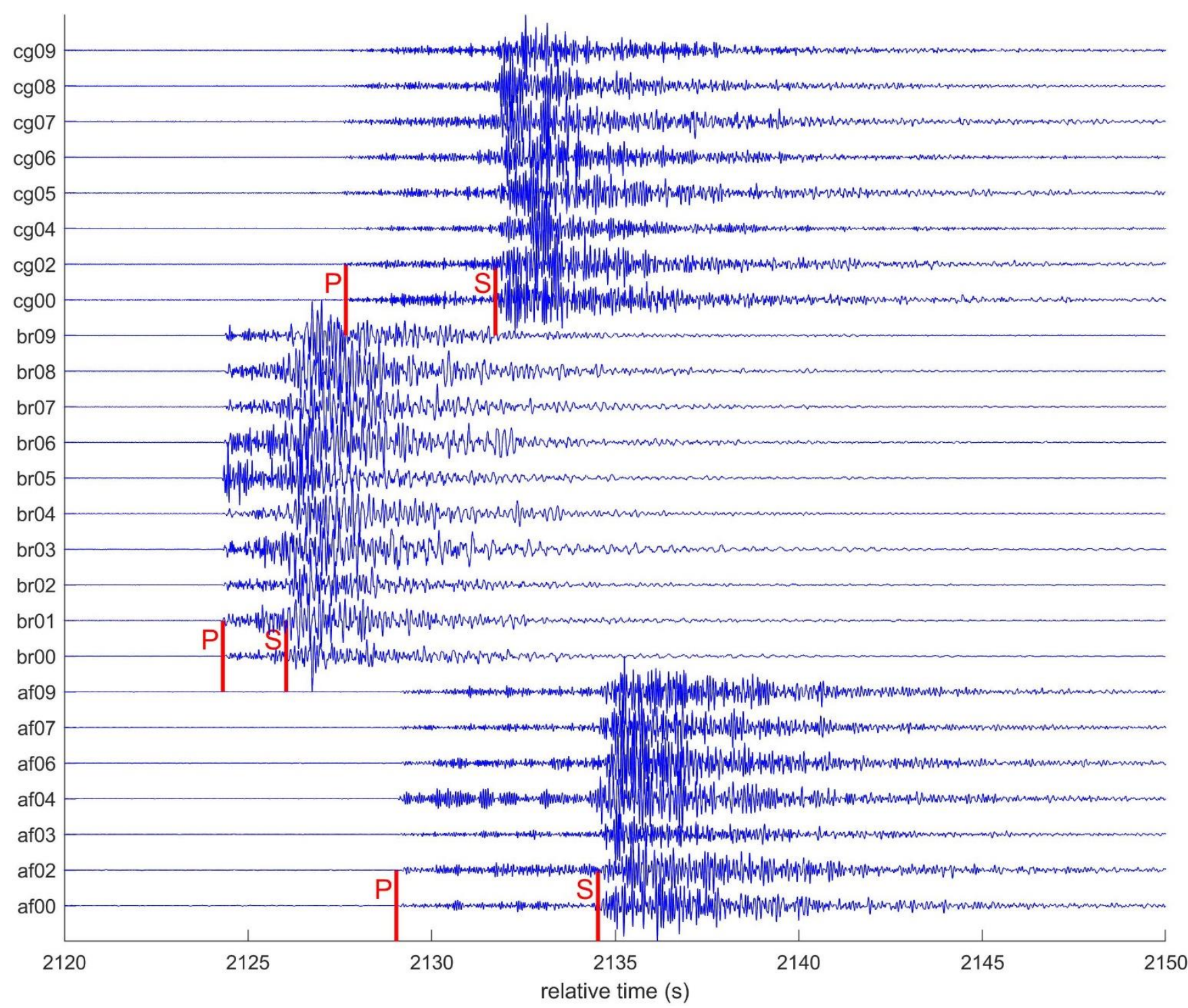

Figure 2: Z-components of the seismogram of an earthquake on 22 July 2017 (23:35 UTC) before the array analysis is performed. 460 Traces are filtered individually according to the spectrogram of each array. Filters applied here are: 2-20 $\mathrm{Hz}$ at array AF, 2-24 $\mathrm{Hz}$ at array BR and 2-21 $\mathrm{Hz}$ at array CG. Red lines mark the P- and S-phases at the central array stations AF00, BR00 and CG00, respectively. 

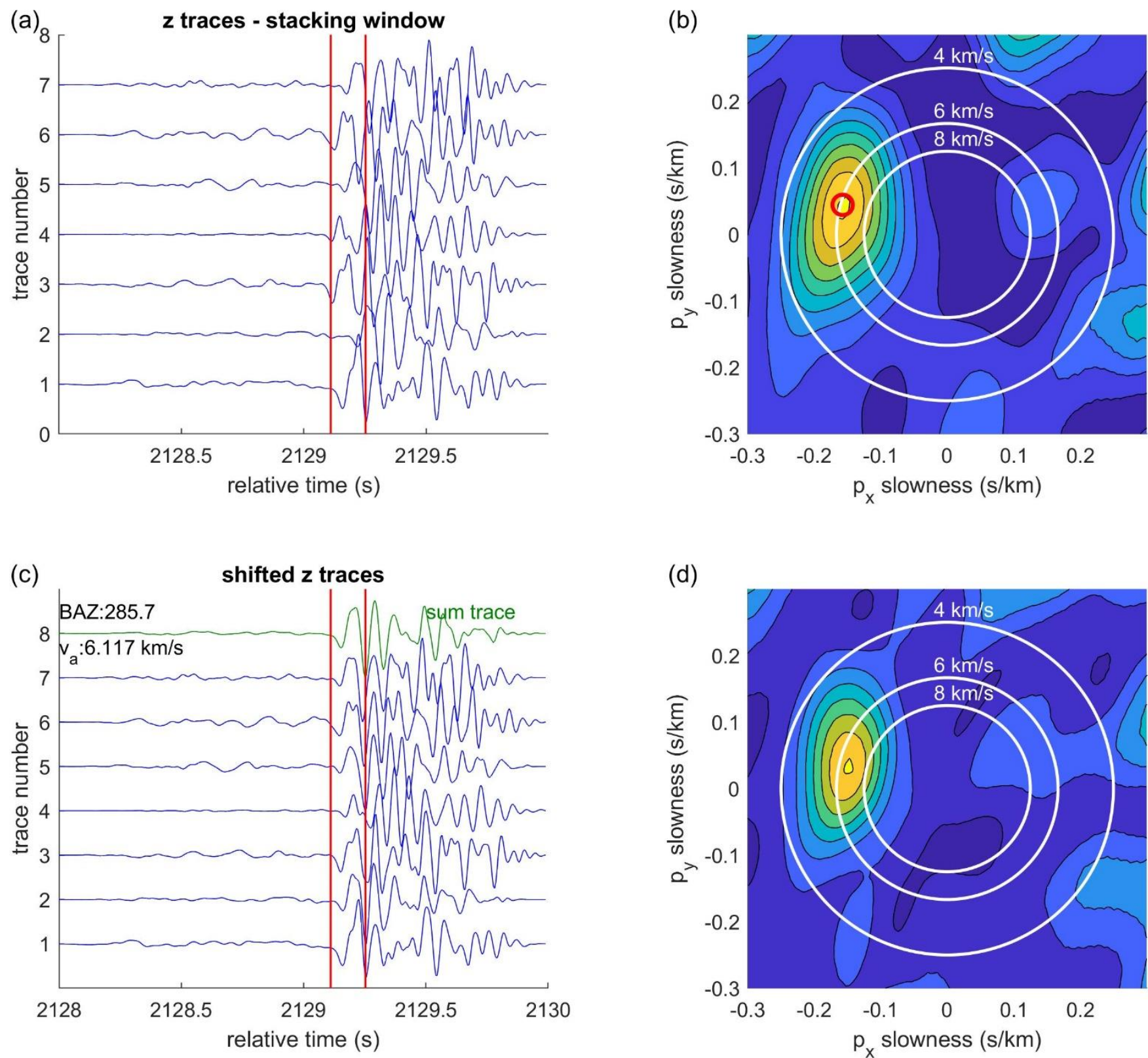

Figure 3: Time-domain array analysis of an earthquake on 22 July 2017 (23:35 UTC) at the array AF. (a) Analysis window of 2 s length with the stacking window marked in red. Traces are displayed before shifting and stacking and are filtered between 2 and 20 Hz. (b) Resulting time-domain energy stack. Red circle: maximum beam energy. (c) Time-shifted traces. The upper green trace represents the sum trace. (d) To retrieve the standard deviation of the backazimuth, the stacking window is varied 100 times by values between -0.2 and $0.2 \mathrm{~s}$. The standard deviation is estimated from the 100 resulting backazimuth values. Shown here is the stack of the 100 energy plots. 

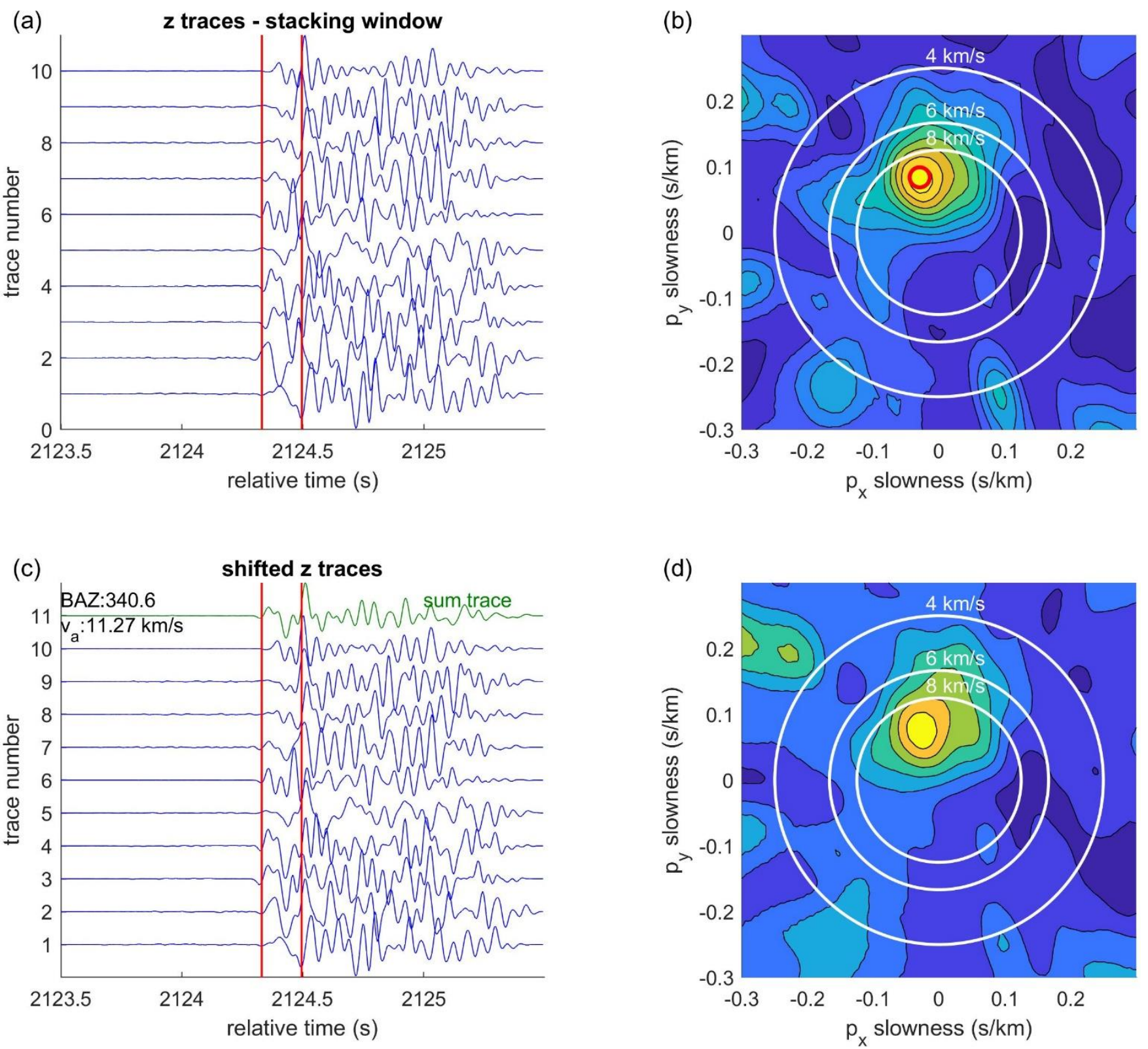

Figure 4: Same as in Figure 3 for array BR. Traces are filtered between 2 and $24 \mathrm{~Hz}$. 

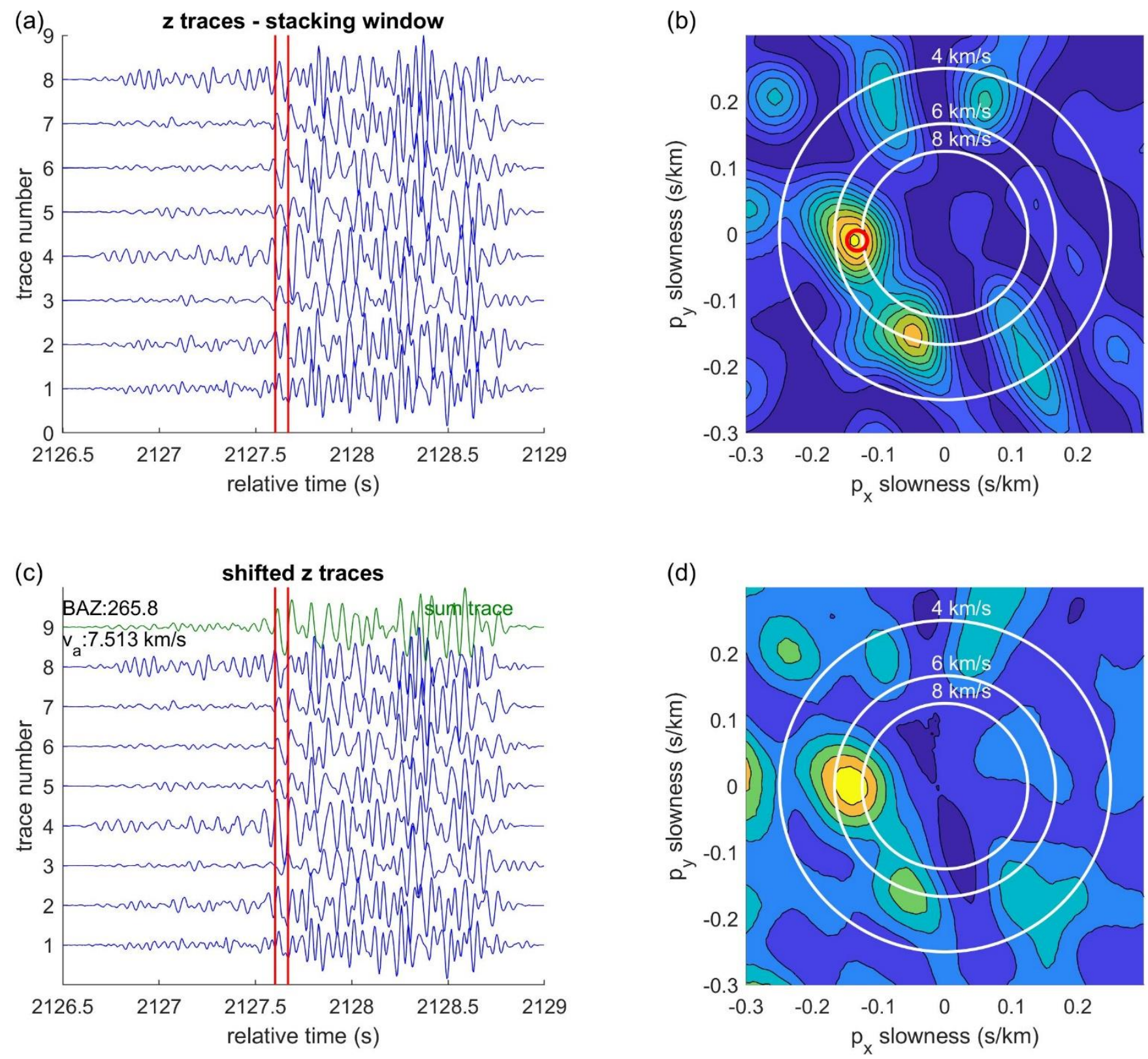

Figure 5: Same as in Figure 3 for array CG. Traces are filtered between 2 and $21 \mathrm{~Hz}$. 


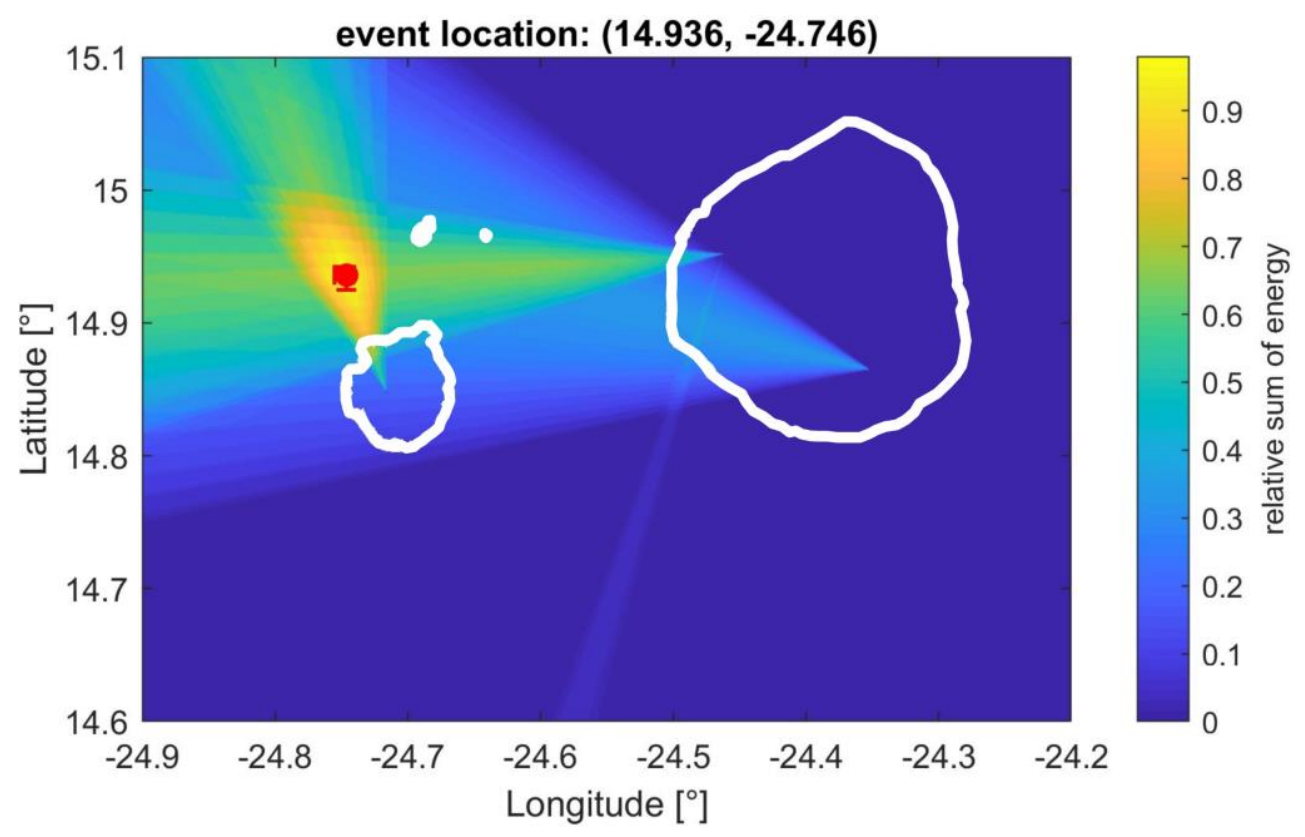

Figure 6: (a) Intersection of the beams projected on a map section, including the coordinates of the arrays and the location of maximum energy estimated. The beams correspond to the beams determined for the example earthquake on $22 \mathrm{July} 2017$ (23:35 UTC). Red circle: event location with error bars. Topographic and bathymetry data are from Ryan et al. (2009). 
https://doi.org/10.5194/se-2021-52

Preprint. Discussion started: 4 May 2021
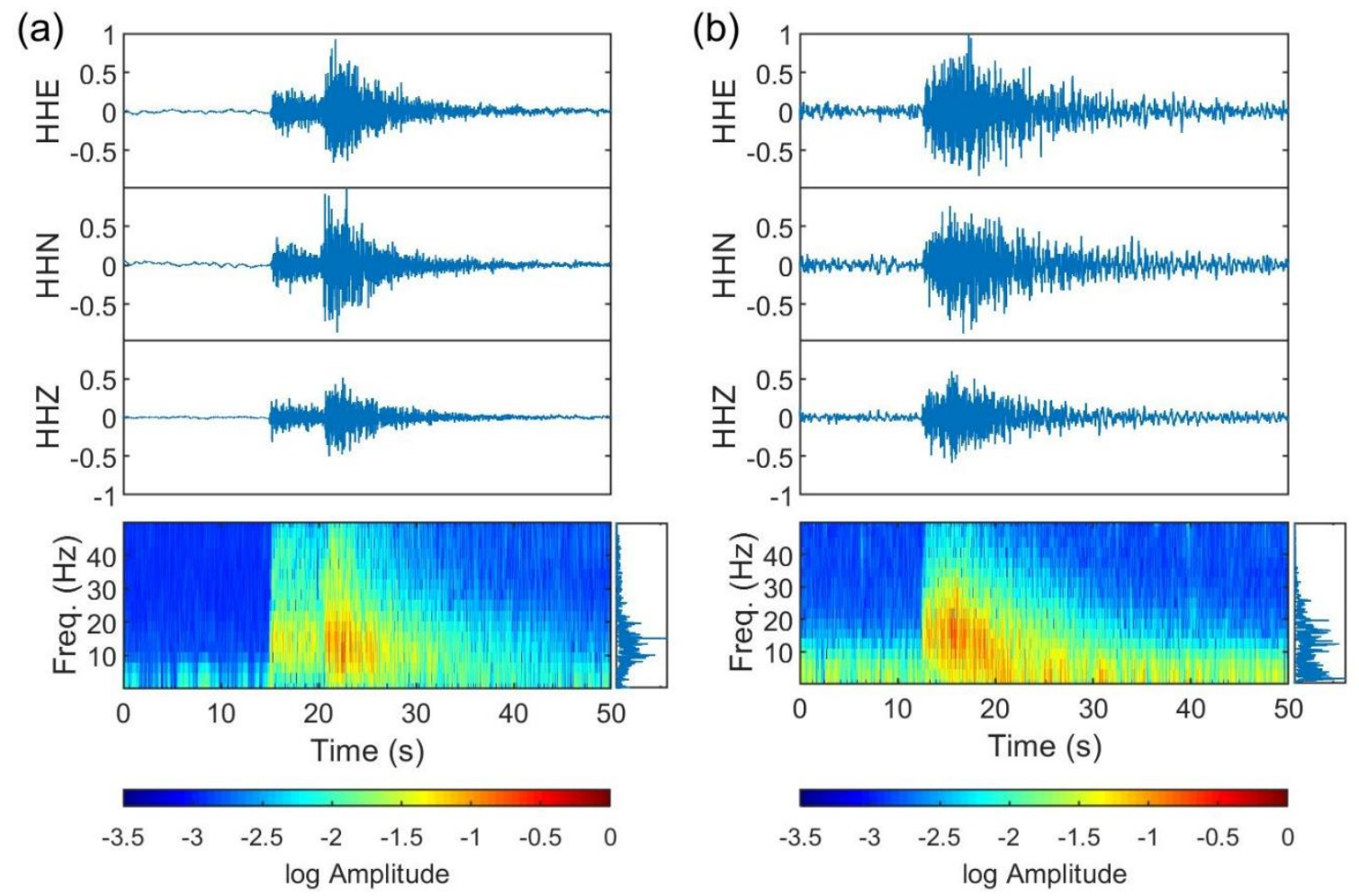

Figure 7: Comparison of a volcano-tectonic earthquake and a hybrid event. (a) Top: Traces of an earthquake occurring on Brava on 22 Feb 2017 (16:44 UTC) recorded at the broad-band station AF02 of array AF on Fogo. Bottom left: spectrogram of the vertical component, bottom right: corresponding frequency content. (b) Traces of a hybrid event recorded on 17 Aug 2017 (02:54 UTC) at the same station. Traces are filtered between 1 and $50 \mathrm{~Hz}$ to remove ocean noise. Bottom left: spectrogram of the vertical component, bottom right: corresponding frequency content. 
https://doi.org/10.5194/se-2021-52

Preprint. Discussion started: 4 May 2021

(c) Author(s) 2021. CC BY 4.0 License.
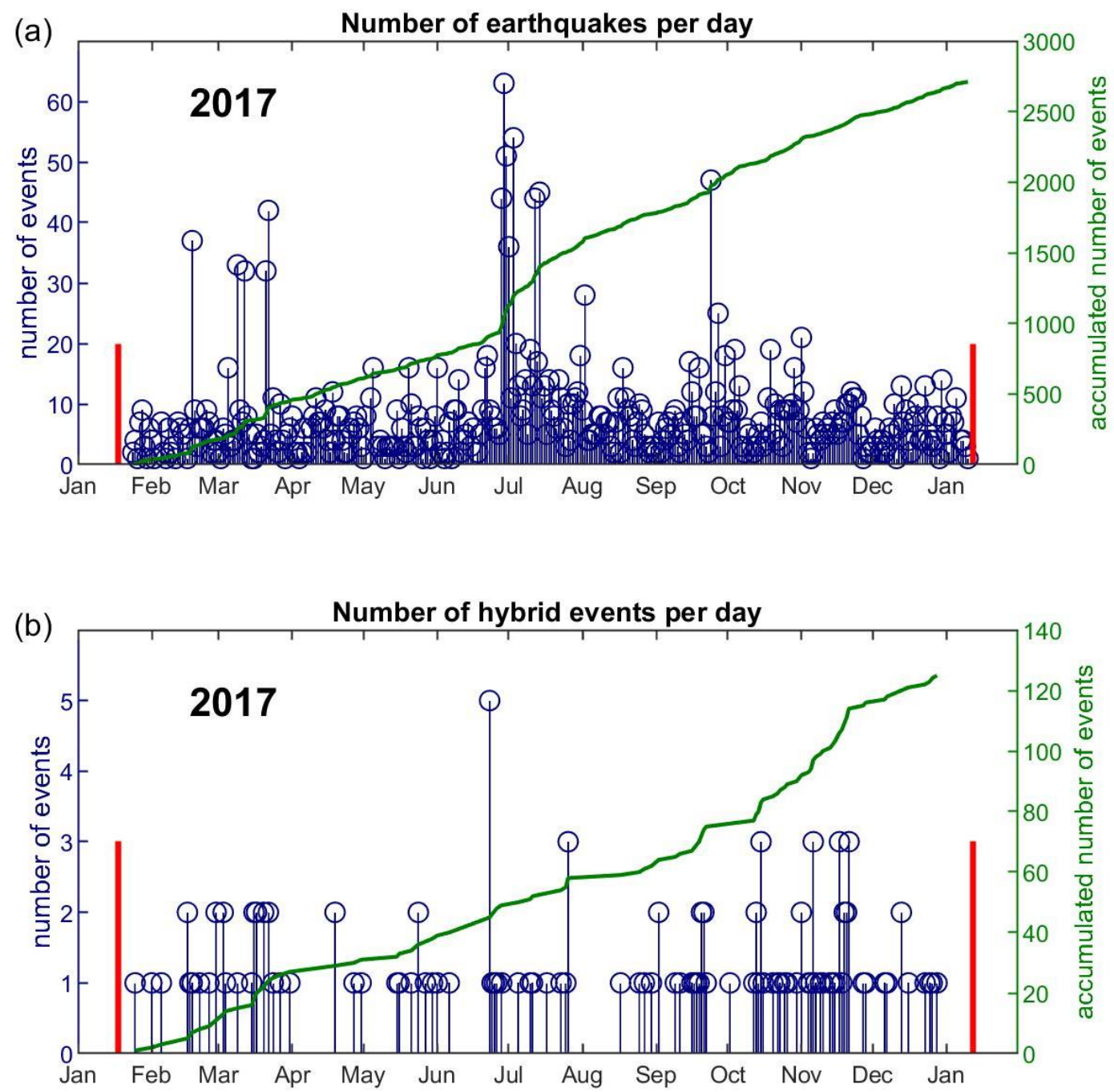

Figure 8: (a) Number of earthquakes per day. Green line: accumulated number of earthquakes. Recordings from 18 January 2017 to 12 January 2018. (b) Number of hybrid events per day. Green line: accumulated number of hybrid events during the same time. 
https://doi.org/10.5194/se-2021-52

Preprint. Discussion started: 4 May 2021

(c) Author(s) 2021. CC BY 4.0 License.
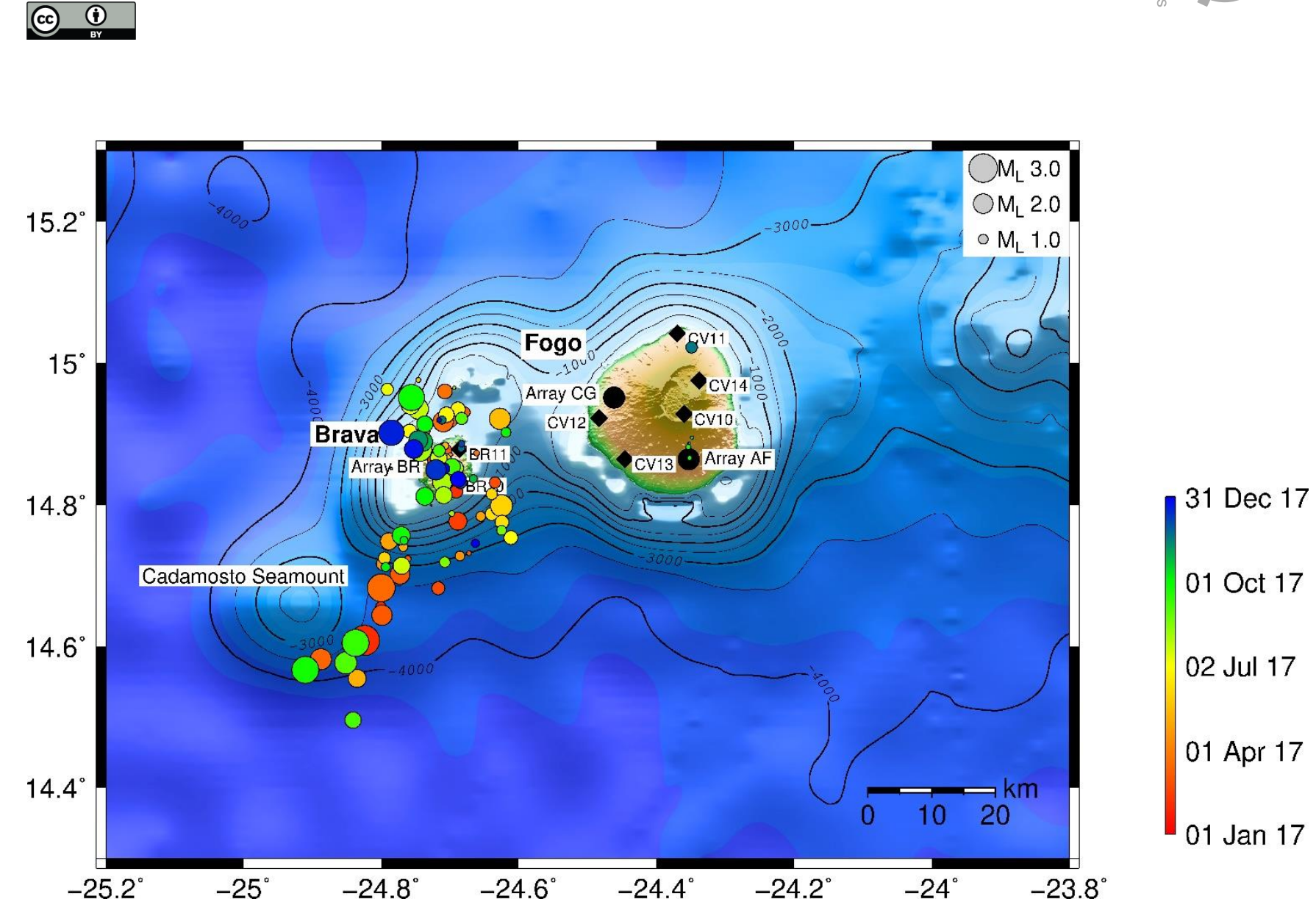

Figure 9: Earthquake locations from 18 Jan 2017 to 12 Jan 2018. Black circles: array locations, black diamonds: short-period single stations. Topographic and bathymetry data are from Ryan et al. (2009).
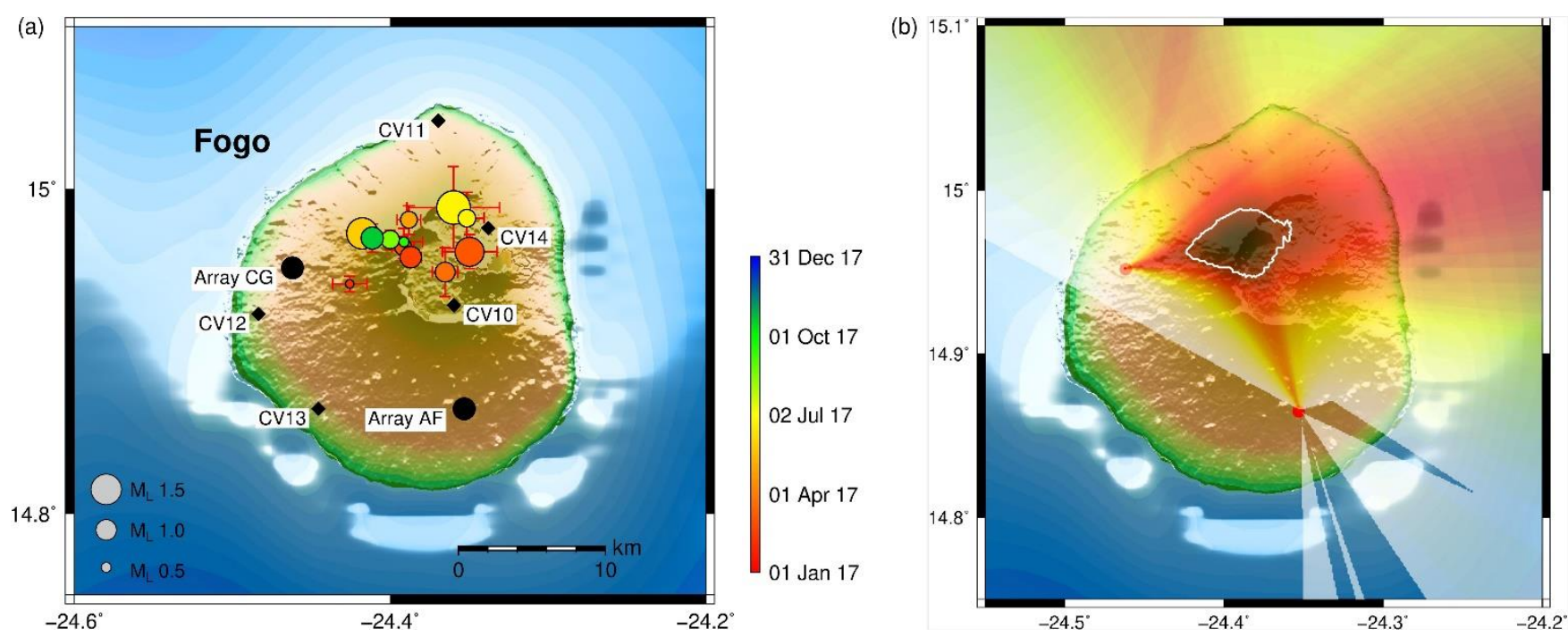

Figure 10: (a) Locations of hybrid events detected between 18 Jan 2017 and 12 Jan 2018, located with the arrays on Fogo. Black circles: array locations, black diamonds: short-period single stations. (b) Superimposed beams of all the hybrid localizations. White line: $80 \%$ of the maximum probability. Topographic and bathymetry data are from Ryan et al. (2009). 
https://doi.org/10.5194/se-2021-52

Preprint. Discussion started: 4 May 2021

(c) Author(s) 2021. CC BY 4.0 License.

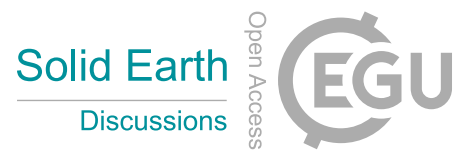

(c) (1)
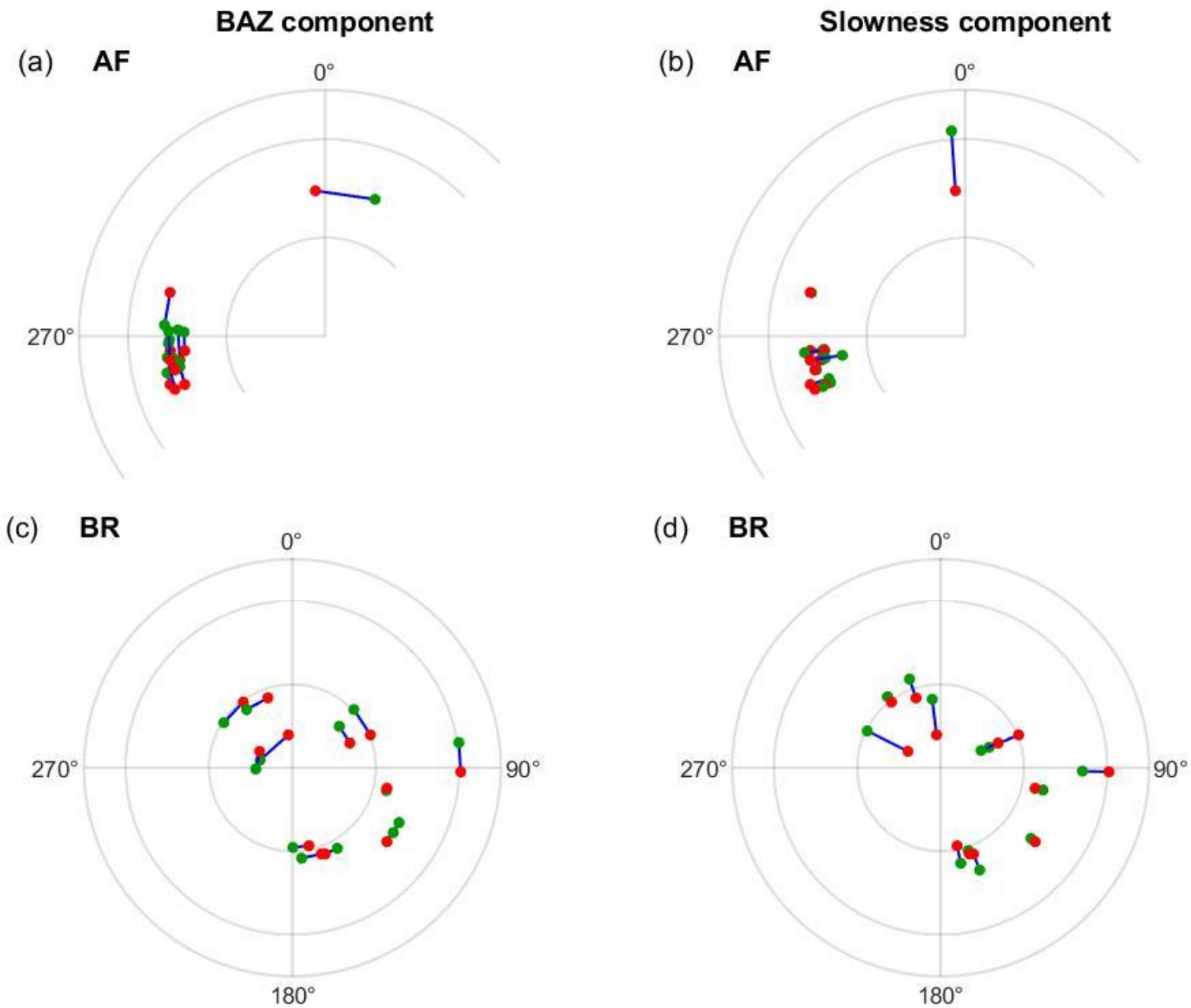

(e) CG

(f) CG
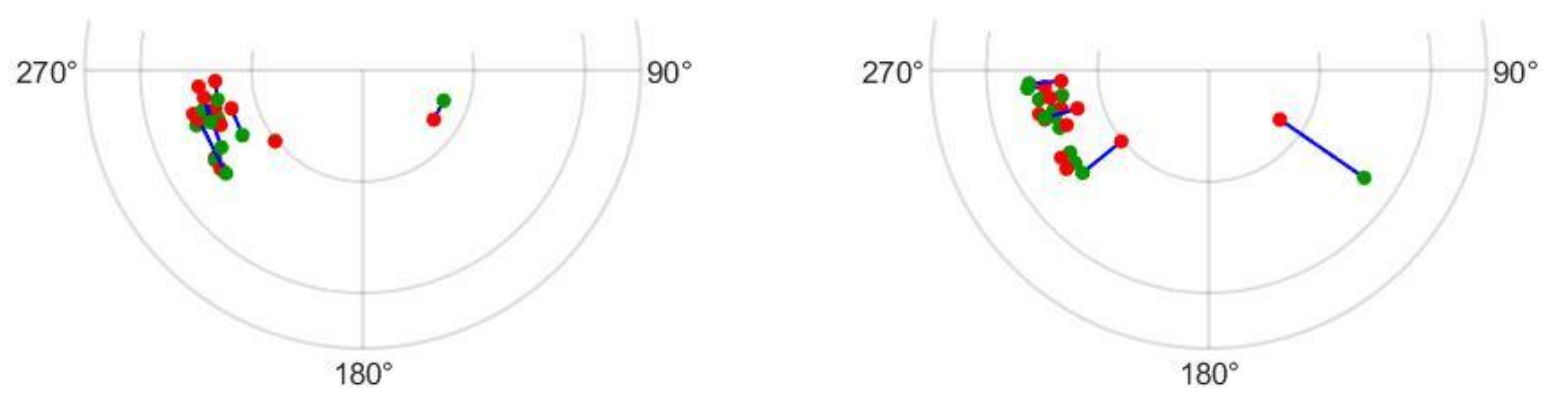

Figure 11: Components of the aberration vectors. The intersections of the radius mark the slowness of $0.1 \mathrm{~s} / \mathrm{km}, 0.2 \mathrm{~s} / \mathrm{km}$ and 0.25 s/km, respectively. (a) Components of the BAZ aberration of array AF, (b) Components of the slowness aberration of array AF, (c) Components of the BAZ aberration of array BR, (d) Components of the slowness aberration of array BR, (e) Components of the BAZ aberration of array CG, (f) Components of the slowness aberration of array CG. Red points: Backazimuth and slowness values of the array analysis, green points: corresponding values of the standard localization. 

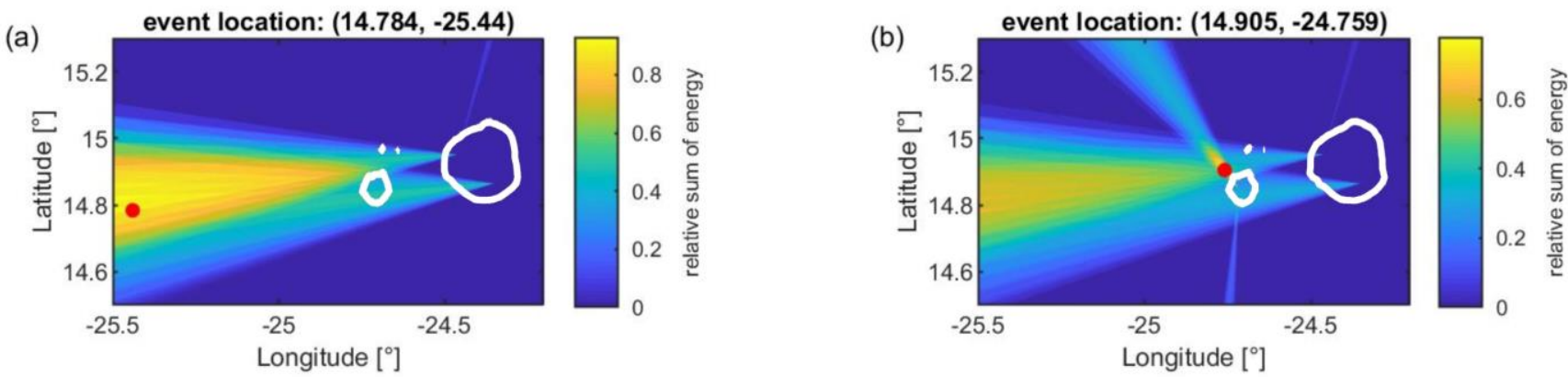

(c)

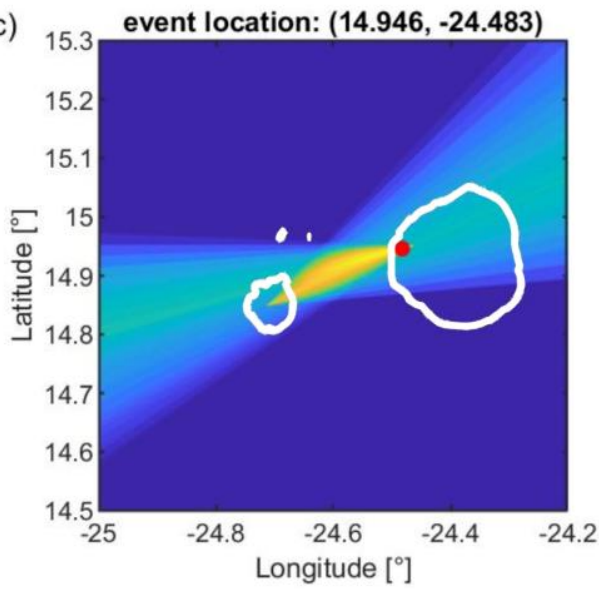

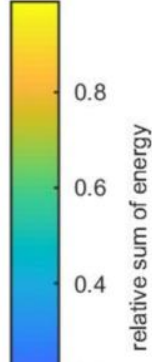

0.2

(d)

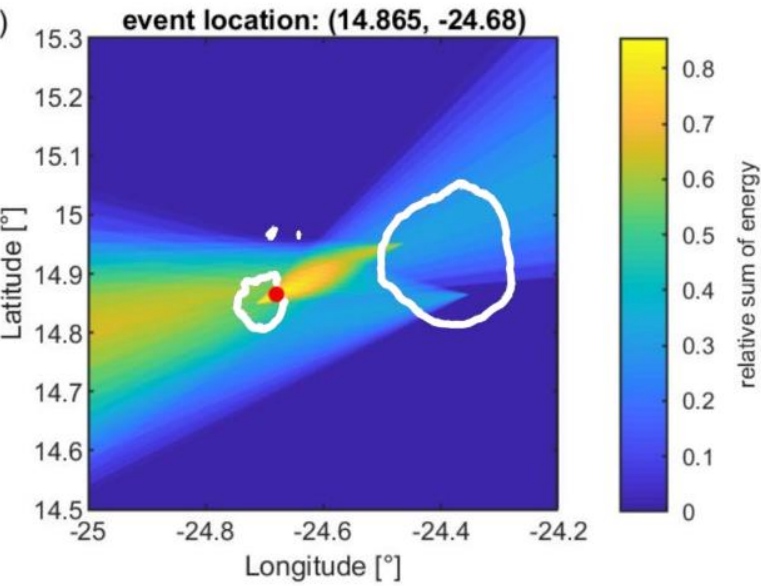

Figure 12: Examples of difficult localizations due to unfavourable source-receiver configurations. (a), (b) Intersection of the beams, (a) without the beam of array BR and (b) with the beam of array BR included. In the case of parallel trending beams (a) the localization of the event is distorted and the beam of the third array is needed (b).

(c), (d) Intersection of the beams, (c) without the beam of array AF and (d) with the beam of array AF included. In the case of beams pointing from one array to another (c) the area of elevated levels spans the area between the two arrays and the localization of the event is distorted. The beam of the third array is needed for a proper localization (d). 


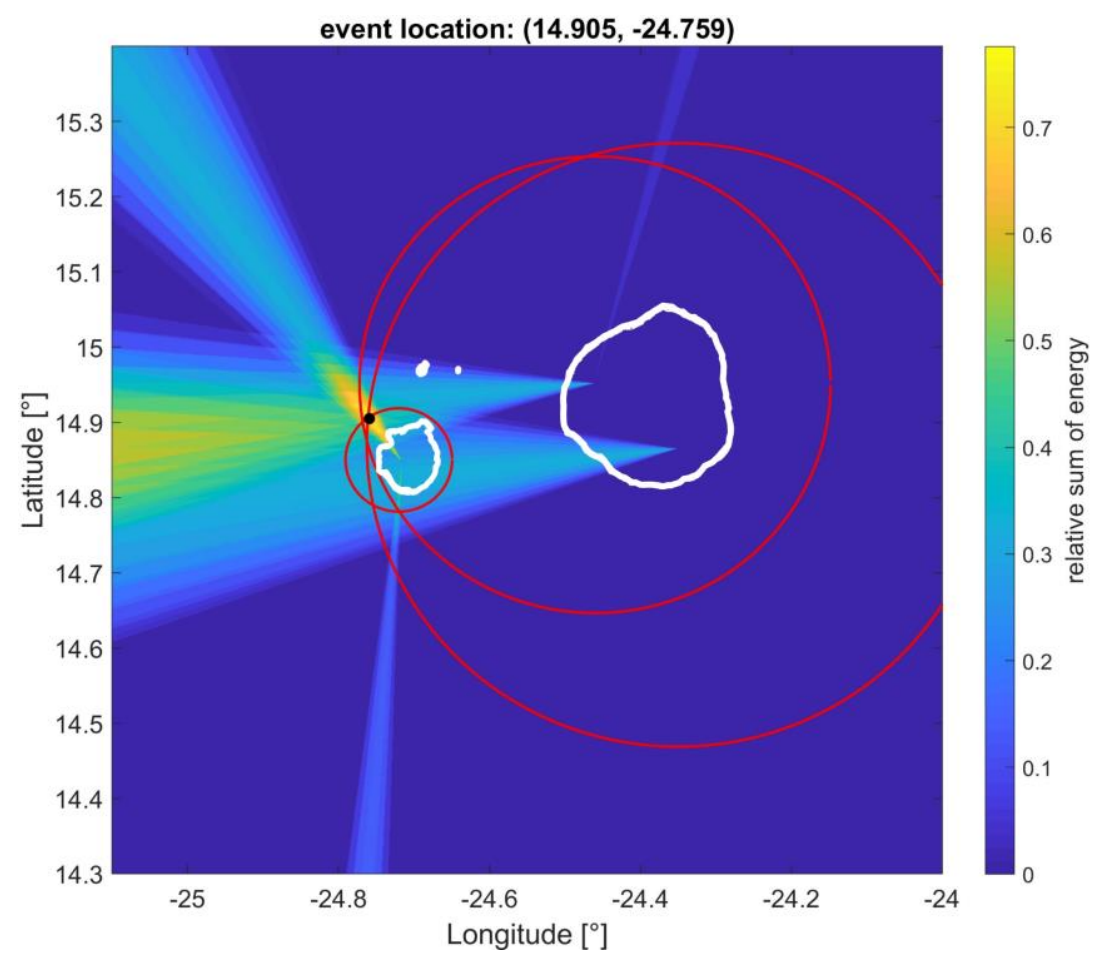

Figure 13: Verification of the result using additional traveltime information, black circle: location of the event derived from intersecting beams, red circles: epicentral distances of the event estimated from $S$ - to P-traveltime differences for the three arrays. The circles give a rough estimate of the expected distance of the event to the array providing a tool to better judge the reliability of the outcome. Note, that this only serves as support for the analyst and is not included in the estimation of the event location. 